\title{
Design Optimization of Power Electronic Transformers in Traction Applications
}

\author{
Sandeep Kumar Chowdhury ${ }^{* a)}$ Non-member, Hiroyasu Kobayashi* Member \\ Keiichiro Kondo* Senior Member
}

(Manuscript received March 11, 2020, revised June 16, 2020)

J-STAGE Advance published date : October 1, 2020

\begin{abstract}
To increase efficiency and reduce weight of low frequency traction transformers (LFTs), many studies have been dedicated to the study and design of power electronic transformers (PETs). Most of these studies have focussed on $16.7 \mathrm{~Hz}$ traction systems and a few on $50 / 60 \mathrm{~Hz}$ systems. PETs offer several degrees of freedom to the designer such as configuration and modulation of power stages, switching frequency, magnetic material etc., which are evaluated based on given specifications to meet the objectives of maximum power density and efficiency. This paper presents a detailed analysis of efficiency and power density of each power stage in a PET with respect to its design parameters. A design methodology is outlined to replace an LFT with an optimally designed PET. To elucidate the design process, the considered case is a $4.16 \mathrm{MW}$ transformer supplied by a $25 \mathrm{KV}, 60 \mathrm{~Hz}$ catenary for a Shinkansen series-700. The configuration of the PET considered is of the indirect type with a cascaded H-bridge as the AC/DC stage interfacing the catenary and a set of parallelly connected DC/DC converters at the output. The best obtained efficiency is $97.7 \%$ with a weight of 1.69 tonnes which is significantly higher than that of the LFT.
\end{abstract}

Keywords: Dual Active Bridge (DAB), Series Resonant Converter (SRC), Medium Frequency Transformer (MFT), ZVS/ZCS (Zero Voltage/Current Switching), American Wire Gauge (AWG)

\section{Introduction}

In present traction systems, the AC supply is fed to a step down transformer operating at low frequency typically $50 / 60$ or $16.7 \mathrm{~Hz}$. The secondary windings (typically three to four) feed a four quadrant voltage source converter operated in PWM mode to control power flow to the traction drive through inverter. These Traction Transformers are bulky and suffer from the problems of low efficiency and poor power density as they are designed for space optimisation. PETs (Power Electronic Transformers) or SSTs (Solid State Transformers) are defined as power electronic systems that converts power between two voltage levels with galvanic isolation between them by Medium Frequency Transformers (MFTs) with full controllability of intermediate voltages and input current. As increase in frequency reduces the size and weight of the transformer the idea is pursued for traction applications. This benefits come at the expense of design complexity and cost. The PET configurations can be broadly classified into two types [Fig. 1]:

1. Direct: In this topology, the AC power received is converted to high frequency AC using cascaded connected matrix converters which is then fed to MFTs whose output is rectified by $\mathrm{AC} / \mathrm{DC}$ converters which feeds the DC link of the inverter of traction drive.

2. Indirect: In this topology, the AC power is first converted

a) Correspondence to: Sandeep Kumar Chowdhury. E-mail: chowdhurysk@fuji.waseda.jp

* Electromobility Sytems Lab, Waseda University

3-4-1, Okubo, Shinjuku-ku, Tokyo 169-8555, Japan to DC by series connected AC/DC converters which is then converted to DC suitable for inverter of traction drive through DC/DC converters. The isolation is provided by the MFTs of DC/DC converters.

The direct type suffers from the problems of current control at zero current crossing and difficulty to obtain soft switching operation. Hence the direct type is more popular and is considered the future of traction ${ }^{(1)}$. Hence this paper focusses on the design optimization of an indirect type PET. Extensive research $^{(2)-(8)}$ has been done to develop PET suitable for $16.7 \mathrm{~Hz}$ systems. Leading industries like ABB, Alstom, Bombardier and Siemens have published their work which pertains to $16.7 \mathrm{~Hz}$ systems. Not enough research is done for $50 / 60 \mathrm{~Hz}$ systems though. Some designs for $50 \mathrm{~Hz}$ traction systems consider SiC IGBTs which entails an undesirable additional cost to the system. In most of the above works, the design is based on a pre-specified frequency and pre-selected configuration \& modulation of secondary power stage (DC/DC) while PET design involves a large number of variables some of which exhibits dependency upon each other and each has a marked effect on the efficiency and power density of the system. Such detailed analysis may not be required for $16.7 \mathrm{~Hz}$ systems as the frequency is low enough to realise benefits on substitution with a PET alone but for $50 / 60 \mathrm{~Hz}$ systems, a detailed analysis of all design parameters is essential. This paper explores optimization in every aspect of design viz. configuration \& modulation strategy of secondary power stage, converter circuit parameters (L, C values), MFT core dimension, winding selection, cooling system design, filter capacitor design etc. To simplify the design process, the volumetric 


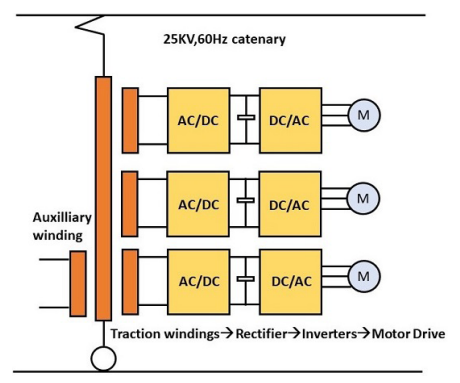

(a) Conventional traction supply system

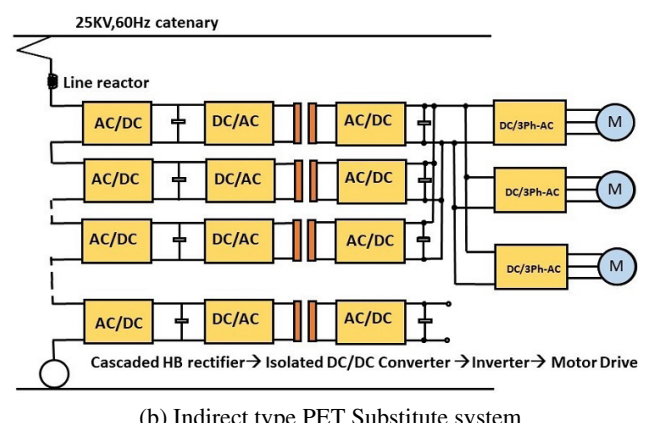

(b) Indirect type PET Substitute system

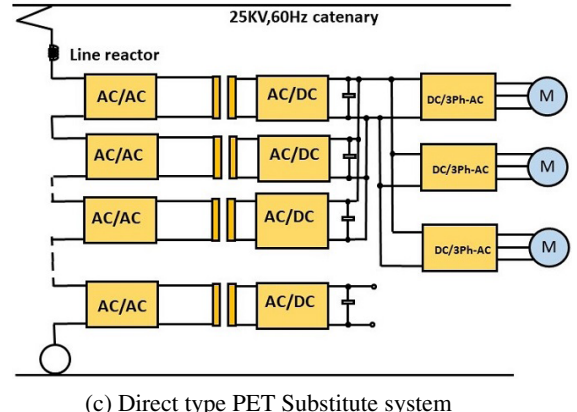

(c) Direct type PET Substitute system

Fig. 1. Reference LFT system and the substitute PET configurations

contribution from the supporting structures and insulating creepage distances have not been considered. The efficiency and power-density analysis is carried out over a range of frequencies to arrive at an optimal set of design variables resulting maximum power density and reasonably high efficiency. To elucidate the design process, the reference considered in this paper is a $4.16 \mathrm{MW}, 25 \mathrm{KV}, 60 \mathrm{~Hz}$ transformer for Shinkansen series-700 [Fig. 1(a)]. The analysis presented in this paper is applicable to any PET design in general. Keeping the cost in mind, the design is done with conventional $\mathrm{Si}$ based devices.

The intermediate bus capacitors decouple the operation and control of power stages and hence both can be designed separately. The design parameters of each power stage for optimization are:

\section{Primary stage-CHB:}

Number of modules (N), switching frequency (f) and line reactor (L).

\section{Secondary stage-DC/DC converter with isolation by} MFT:

The configurations viz. DAB, SRC and modulation strategies for soft-switching. The design variables corresponding to each selection are the turns ratio of the MFT (n) and the tank circuit parameters viz. L-for DAB and L, C-for SRC.

The MFT design is carried out iteratively by varying the core dimensions and winding parameters viz. number of strands and strand's AWG considering the integration of the leakage inductance into the tank circuit, provision of requisite isolation, efficient utilisation of the window area and operation within thermal limits. The design of DC/DC converter and the MFT is done over a wide frequency range to find the optimum value for highest power density and acceptable losses. The dielectric losses in the capacitors and Gate drive losses are neglected in comparison to device and core losses.

\section{Design of Primary Stage: Cascaded H-Bridge AC/DC Converter}

The input $\mathrm{CHB}$ interfaces with the $25 \mathrm{KV}$ catenary, provides sharing of the voltage among the devices. An N module $\mathrm{CHB}$ generates a $(2 \mathrm{~N}+1)$ level output voltage waveform which improves the harmonic performance and reduces the filtering requirement. The total DC link voltage, $V_{\text {dctot }}$ required for a nominal modulation index (MI) of 0.95 is given by:

$$
V_{d c t o t}=\frac{V_{s p k}}{M I}=\frac{25 \sqrt{2}}{0.95} K V=37.21 K V \cdots \cdots \cdots
$$

Where $V_{s p k}$ is the peak catenary voltage. The number of modules, $\mathrm{N}$ is decided by the device's blocking voltage, $V_{B}$ given by:

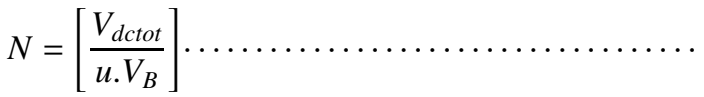

where $\mathrm{u}$ is the blocking voltage utilization factor belongs in the range $[0.5,0.6]$ and [. ] represents greatest integer function.

1. Device with low $V_{B}$ requires higher $\mathrm{N}$ which increases the effective switching frequency by $\mathrm{N}$ times reducing the size of the filter reactor. The switching loss per pulse will decrease but the conduction loss will increase as large number of devices are in series. In addition the reliability concerns arises. 2. Device with high $V_{B}$ requires low $\mathrm{N}$, hence high frequency or bigger size filter will be required to limit line current ripples. The switching losse per pulse is higher but the conduction losses will decrease.

Considering the points above, the design is done with 6.5 KV Si IGBTs to have low number of modules, limit conduction losses and restrict the reliability issues.

Hence $\mathrm{N}=11$ modules are required and each $\mathrm{CHB}$ cell will be having average voltage, $V_{c}$ of $3.83 \mathrm{KV}$.

2.1 Operation Principle of CHB The CHB performs the following functions:

(a) Shaping the input current, controlling the input power factor to unity.

(b) Maintaining voltage balance across the DC bus capacitors.

These objectives are met by a set of voltage and current controllers which generates the control voltage, $V_{r}$ which is modulated by a modulator which follows a voltage balance strategy to synthesize it from N CHB cells by generating appropriate switching functions for each cell. For unity power factor operation, $V_{r}$ is given by (Neglecting resistive drop) [Fig. 2(b)]:

$$
V_{r}=\sqrt{V_{s p k}^{2}+\left(I_{s p k} \cdot \omega \cdot L\right)^{2}} \cdot \sin (\omega \cdot t-\phi) ; \phi=\tan ^{-1}\left(\frac{I_{s p k} \omega \cdot L}{V_{s p k}}\right)
$$

To keep the switching losses low, hybrid modulation is deployed in the design as it takes the advantage of both low frequency (stepped modulation) and high frequency PWM techniques ${ }^{(9)}$. At any instant only a single cell operates in PWM mode while the rest are fully ON or OFF. The reference voltage, $V_{r}$ is divided into equal sections with the scale 


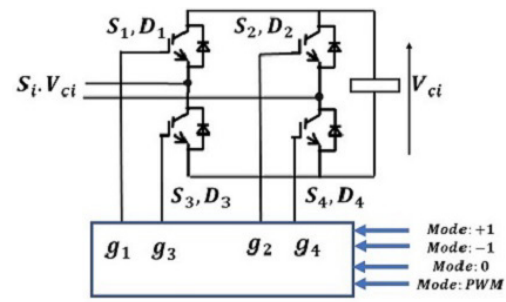

(a) $\mathrm{CHB}$ cell with driver circuit

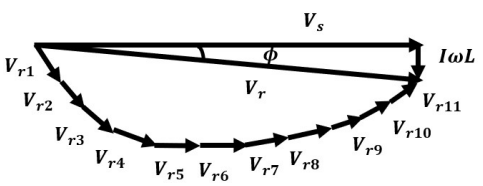

(b) Vector diagram of $\mathrm{CHB}$

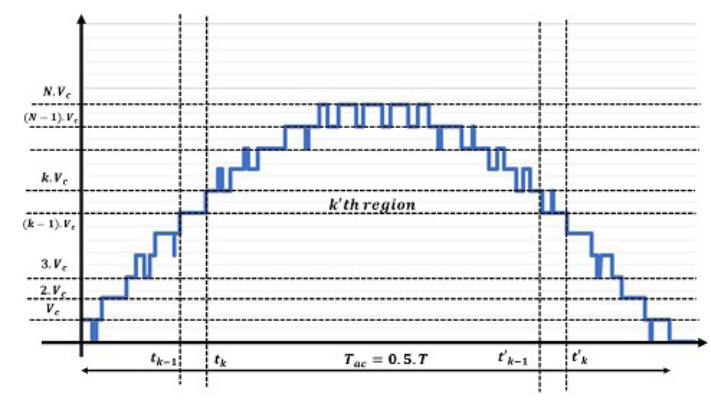

(c) Operation of the $\mathrm{CHB}$ in region $\mathrm{k}$

Fig. 2. Multilevel operation of CHB

of $V_{c}$ [Fig. 2(c)]. The region $\mathrm{k}$ is defined as:

$$
(k-1) . V_{c} \leq\left|V_{r}\right| \leq k \cdot V_{c} ; k=1,2, \ldots N .
$$

Hence if the reference voltage lies in region $\mathrm{k}, \mathrm{k}$ cells are required to synthesize it. The voltage region $\mathrm{k}$ can be represented by the time intervals $\left(t_{k-1}, t_{k}\right)$ and $\left(t_{k-1}^{\prime}, t_{k}^{\prime}\right)$ as well which are given by:

$$
t_{k}=\frac{1}{\omega} \sin ^{-1}\left(\frac{k \cdot V_{c}}{V_{r p k}}\right) ; t_{k}^{\prime}=\frac{\pi}{\omega}-t_{k} \ldots \ldots \ldots \ldots \ldots \ldots
$$

To maintain the voltage balance among cells, the controller follows "sort and balancing" algorithm. The cell voltages are sampled at the fundamental frequency $\left(f_{o}=60 \mathrm{~Hz}\right)$ and the digital controller determines the voltage region $\mathrm{k}$ and then sorts them in ascending/descending order based on the sign of current which determines the charge/discharge operation. This ensures that the cells with lowest voltages are charged and cells with highest voltages are discharged to maintain the voltage balance. The possible operation modes of a CHB cell are:

1. Mode 0: $S_{1}, S_{2}$ or $S_{3}, S_{4}$ are switched on and the output voltage is 0 .

2. Mode 1: $S_{1}, S_{4}$ are switched on and the output voltage is $V_{c}$.

3. Mode $-1: S_{2}, S_{3}$ are switched on and the output voltage is $-V_{c}$.

4. Mode PWM: Depending on the sign of PWM voltage, Mode 1 (for positive) or -1 (for negative) is maintained for a period D. $T_{s}$ and Mode 0 is maintained for $(1-D) T_{s}$ where $T_{s}$ is the switching period and $\mathrm{D}$ is the duty ratio given by:

$$
D=\frac{\left|V_{r p k} \cdot \sin (\omega \cdot t-\phi)\right|-(k-1) \cdot V_{c}}{V_{c}}
$$

The voltage waveform synthesized by the modulator can be represented by:

$$
V_{r, \text { mod }}=\sum_{i=1}^{N} S_{i} . V_{c i}
$$

where $S_{i}$ and $V_{c i}$ are the switching function and voltage of the i'th cell [Fig. 2(a)] respectively. When $V_{r}$ is in region k, (k-1) cells are switched with $S_{i}=\operatorname{sign}\left(V_{r}\right)$ and the k'th cell is modulated in PWM mode given by $S_{k}=\operatorname{sign}\left(V_{r}\right)$. D. The rest (N-k) cells are assigned $S_{i}=0$.

2.2 Semiconductor Loss Analysis

There will be three modes of device loss in a CHB:

1. Conducton losses: For analytical calculation, threshold voltage, $V_{T}$ and the device resistance, $R_{d}$ corresponding to specified junction temperature $\left(T_{j}=125^{\circ} \mathrm{C}\right.$ here $)$ are taken from datasheet which allows calculation of device conduction losses in the form:

$$
P_{\text {cond }}=\int_{t_{K-1}}^{t_{K}}\left(V_{T} \cdot i+i^{2} \cdot R_{d}\right) d t
$$

When the operation region is $\mathrm{k}$,

(i) (k-1) cells operate in mode 1 . Current is conducted by $D_{1}$ and $D_{4}$

(ii) $(\mathrm{N}-\mathrm{k})$ cells operate in mode 0 . Current is conducted by $S_{3}$ and $D_{4}$

(iii) k'th cell operate in mode PWM. Current is commutated between $S_{3}$ and $D_{1}$ with the switching frequency $f_{s}$ and with $S_{4}$ completely ON.

Conduction losses in $\mathrm{D}_{4}$ for all cells:

$$
P_{D_{4}}=\frac{2 I_{s p k} N V_{d o}}{\pi}+N \frac{I_{s p k}^{2}}{2} r_{d} .
$$

Conduction losses in $D_{1}$ for all cells:

$$
\begin{aligned}
P_{D_{1}}= & \frac{2 \cdot I_{s p k} \cdot V_{d o}}{\pi} \cdot \sum_{k=1}^{N-1} \cos \left(\omega \cdot t_{k}\right) \\
& +\frac{I_{s p k}^{2} \cdot r_{d}}{T_{a c}} \cdot \sum_{K=1}^{N-1}\left\{\left(t_{N}-t_{k}\right)+\frac{1}{2 \omega} \cdot \sin \left(2 \omega \cdot t_{k}\right)\right\} \cdots
\end{aligned}
$$

Conduction losses in $S_{3}$ operating in mode 0 for all cells:

$$
\begin{aligned}
P_{S_{3}}= & \frac{2 . I_{s p k} \cdot V_{c e o}}{\pi} \cdot \sum_{k=1}^{N-1} V_{c e o}\left\{1-\cos \left(\omega \cdot t_{k}\right)\right\} \\
& +\frac{I_{s p k}^{2} \cdot r_{c e}}{T_{a c}} \cdot \sum_{k=1}^{N-1}\left\{t_{k}-\frac{1}{2 \omega} \cdot \sin \left(2 \omega \cdot t_{k}\right)\right\} \cdots \cdots
\end{aligned}
$$

Conduction losses in $D_{1}$ operating in PWM mode:

$$
\begin{aligned}
P_{D_{1 P W M}} & \approx \frac{2}{T_{a c}} \sum_{k=1}^{N} \Delta t_{k} V_{d k, a v g}\left(I_{s P W M}\right)_{k} \\
& =\frac{2}{T_{a c}} \sum_{k=1}^{N} \Delta t_{k}\left(V_{d o}+I_{s p k} \cdot r_{d} \cdot \frac{(2 k-1) V_{c}}{2 V_{s p k}}\right)\left(I_{s P W M}\right)_{k}
\end{aligned}
$$

where $\Delta t_{k}=t_{k}-t_{k-1}$ and $V_{d k, a v g}$ is the average voltage drop 
across the diode in region $\mathrm{k}$ which can be approximated by:

$$
\begin{aligned}
V_{d k, a v g} & =V_{d o}+I_{a v g} \cdot r_{d} \cdot \approx V_{d o}+\frac{I_{s p k}}{2} \cdot r_{d} \cdot\left\{\sin \left(\omega \cdot t_{k}\right)+\sin \left(\omega \cdot t_{k-1}\right)\right\} \\
& =V_{d o}+\frac{I_{s p k}}{2} \cdot r_{d} \cdot\left(\frac{k \cdot V_{c}}{V_{s p k}}+\frac{(k-1) \cdot V_{c}}{V_{s p k}}\right) \ldots \ldots \ldots(13)
\end{aligned}
$$

Similarly, conduction losses in $S_{3}$ operating in PWM mode:

$$
P_{S_{3 P W M}}=\frac{2}{T_{a c}} \sum_{k=1}^{N} \Delta t_{k}\left(V_{c e o}+I_{s p k} \cdot r_{c e} \cdot \frac{(2 k-1) V_{c}}{2 V_{s p k}}\right)\left(I_{s}-I_{s P W M}\right)_{k}
$$

Thus the total semiconductor losses for the $\mathrm{N}$ cells can be analytically expressed as:

$$
P_{\text {cond }}=P_{D_{4}}+P_{D_{1}}+P_{S_{3}}+P_{S_{3 P W M}}+P_{D_{1 P W M}} \cdots
$$

Where $V_{d o}$ is the diode forward drop. $V_{c e o}$ is the collectoremittor threshold voltage. $r_{d}$ and $r_{c e}$ are their resistances respectively. $t_{k}$ is the instant the voltage region changes and $\left(I_{P W M}\right)_{k}$ and $\left(I_{s}\right)_{k}$ are the average currents in PWM mode and mode- 1 in kth region respectively whose calculations are given in Appendix-I.

2. PWM Switching losses: In traction mode, switching losses occurs in $S_{3}$ during turn on and and off and reverse recovery happens in $D_{1}$ during turning on of $S_{3}$. Assuming that the switching energy dissipation is linearly dependent on the collector current, the average switching loss over the mains half cycle can be calculated by:

$$
P_{s w, P W M}=\frac{2 . f_{s}}{T_{a c}} \sum_{k=1}^{N} \Delta t_{k} \cdot\left(E_{o n}+E_{o f f}+E_{r e c}\right) \cdot \frac{V_{c} \cdot\left(I_{s}\right)_{K}}{V_{R} \cdot I_{R}}
$$

Where $\Delta t_{k}=\left(t_{k}-t_{k-1}\right) E_{\text {on }}$ and $E_{\text {off }}$ are turn-on and turn-off losses at rated voltage of $V_{R}$ and rated current $I_{R}$ obtained from the device datasheet.

3. Voltage balancing switching losses: This component of switching loss is due to the change in operating mode with the sampling frequency $f_{o}$ (changing from 0 to 1 and vice versa). The value of $f_{o}$ chosen in design is the supply frequency i.e., $60 \mathrm{~Hz}$ ensuring low voltage balancing switching losses. In region $\mathrm{k},(\mathrm{k}-1)$ cells operate in mode 1 and $(\mathrm{N}-\mathrm{k})$ cells operate in mode 0 , so the number of transitions from 0 to 1 must be equal to the transitions from 1 to 0 .Thus the maximum number of transitions is the minimum of $(\mathrm{k}-1)$ and (N-k). Thus the maximum switching loss is given by:

$$
\begin{aligned}
& P_{s w, V B}=\frac{2 \cdot f_{o}}{T_{a c}} \sum_{k=1}^{N} \Delta t_{k} \cdot \min (k-1, N-k) \\
& \left(E_{\text {on }}+E_{\text {off }}+E_{\text {rec }}\right) \cdot \frac{V_{c} \cdot\left(I_{s}\right)_{K}}{V_{R} \cdot I_{R}} \ldots \ldots \ldots \ldots
\end{aligned}
$$

In regeneration mode, roles of $D_{1}, S_{3}, D_{4}$ are taken by $D_{2}$, $S_{1}, D_{3}$ respectively. Hence the associated losses are the same as calculated for the former mode.

2.3 Reactor Design The reactor required to limit peak to peak line current ripple at frequency $f_{s}$ with hybrid modulation discussed above is given by:

$$
\Delta I_{s p p, \max }=\frac{V_{d c t o t}}{4 . N \cdot f_{s} \cdot L} ; L \geq \frac{V_{d c t o t}}{4 . N \cdot f_{s} \cdot \Delta I_{s p p, \max }} \cdots \cdots
$$

An air core reactor will require large number of turns increasing the ohmic losses and its susceptible to stray magnetic fields. Hence an iron core reactor with EE-type core and material- amorphous iron 2605SA1 is designed. As the PWM high frequency component of the current is very small, litz type winding with lower AWG is sufficient. Selected AWG $=28$, strand diametre, $d_{s}=.32 \mathrm{~mm}$. The design constraints are:

- The core does not saturate at twice the rated peak current which may occur during fault conditions. Hence the peak flux density in the core is limited to $50 \%$ of $0.8 B_{\text {sat }}$. The factor of 0.8 is taken before the saturation flux density ( $=1.56 \mathrm{~T}$ for amorphous iron) to impose linearity.

- Limitation of peak to peak current ripple to $5 \%$ [Fig. 3(c)].

- Surface temperature should not exceed beyond $100^{\circ} \mathrm{C}$ at full load for an ambient of $50^{\circ} \mathrm{C}$ with forced air cooling. The design steps are:

(1) Number of strands, $n_{s}$ to limit current density $J_{m}$ is calculated.

$$
n_{s}=\frac{4 \cdot I_{s p k}}{\pi \cdot d_{s}^{2} \cdot J_{m}} \ldots
$$

(2) Area product is calculated,

$$
A_{p}=\frac{L \cdot I_{s p k}^{2}}{B_{m} . J_{m} \cdot K_{w}} \cdots
$$

where $B_{m}=$ Peak flux density, $K_{w}=$ Window utilisation factor, $I_{s p k}=$ Peak current.

(3) Sweep over dimensions of core, keeping the dimensional ratios for an EE type core. Calculate core and window areas- $A_{c}, A_{w}$.

(4) Calculate the number of turns, $\mathrm{N}$ and window factor, $K_{w}$

$$
N=\left[\frac{L \cdot I_{m}}{B_{m} \cdot A_{c}}\right] ; K_{w}=\frac{N \cdot n_{s} \cdot \pi \cdot d_{s}^{2}}{A_{w}} \cdots \cdots \cdots
$$

(5) Length of air-gap in the central limb required [Fig. 3(b)],

$$
l_{g}=\frac{\mu_{o} \cdot N \cdot I_{m}}{B_{m}}-\frac{l_{m a g}}{\mu_{r}} \ldots \ldots \ldots \ldots \ldots \ldots \ldots
$$

where $l_{\text {mag }}$ is the magnetic path of the core considering the magnetic circuit of the core and $\mu_{r}=4200$ is the relative permeability of the core corresponding to $B_{m}$.

(6) Calculate Fringing factor

$$
F_{g}=1+\frac{l_{g}}{\sqrt{A_{c}}} \cdot \log \left(\frac{2 h_{w}}{l_{g}}\right) \ldots
$$

Readjust the turns number $N^{\prime}=\frac{N}{\sqrt{F_{g}}}$. where $h_{w}=$ Height of core.

(7) The thermal limit is observed by assuming a surface heat transfer coefficient of $60 \mathrm{~W} /\left(\mathrm{m}^{2} \mathrm{~K}\right)$ (typical value for forced cooling) ${ }^{(10)}$, an ambient temperature of $50^{\circ} \mathrm{C}$, and a maximum allowable surface temperature of $100^{\circ} \mathrm{C}$.

If $K_{w} \geq 30 \%$ within thermal limit, the design is accepted else another set of core dimensions is taken from step 1 and the steps 2-6 are repeated.

This is followed by the calculation of the losses and boxed volume of the reactor. The losses include:

(a) The high frequency core losses $P_{c H F}$ due to the PWM swithcing pulsations. 


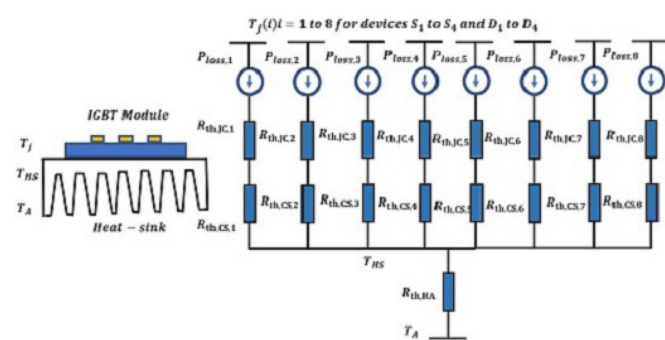

(a) Thermal model of a CHB module

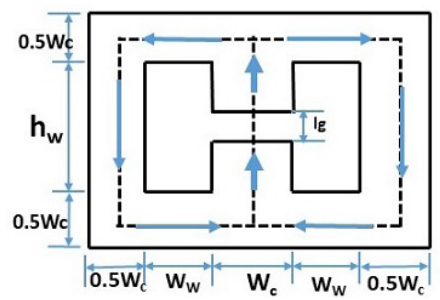

(b) Magnetic path of reactor

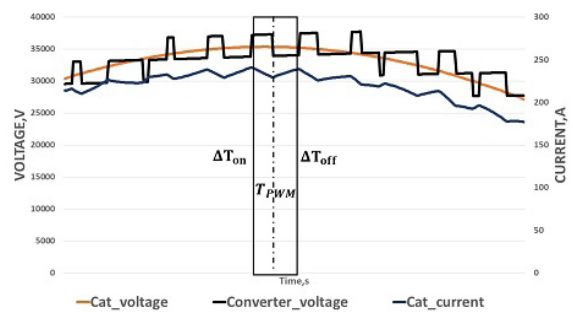

(c) Line current ripples

Fig. 3. Primary stage design models

(b) The low frequency core loss $P_{c L F}$ which is due to the fundamental frequency of the supply.

(c) The ohmic losses in winding which are calculated for round solid copper wires, neglecting HF losses in the winding, which is a feasible approximation since the inductor current equals the grid current, where harmonics above $1 \mathrm{kHz}$ are limited to below $1 \%$ by IEEE 519 .

The losses (a) and (b) are calculated by improved Generalised Steinmitz Equation (i-GSE) ${ }^{(11)}$ detailed in Appendix-II.

2.4 Heat Sink Modelling and Design The heat sink in each module removes the heat dissipated across the devices and maintain the junction temperature at $125^{\circ} \mathrm{C}$. The thermal resistances values obtained from the device datasheet alongwith the loss generated in each device can be used to calculate the thermal resistance of the heatsink required for an ambient temperature of $50^{\circ}$. The equivalent thermal circuit is shown in [Fig. 3(a)]. The maximum allowable temperature of heatsink is calculated as:

$$
T_{H S, \max }=\min _{i}\left(T_{j}-P_{\text {loss }, i} \cdot R_{t h, J H i}\right)
$$

where $R_{t h, J H i}$ is the thermal resistance between device's junction to heatsink obtained from datasheet as $=R_{t h, J C i}+R_{t h, C S i}$ and $P_{\text {loss }, i}$ is the average device loss. Thermal resistance of the heatsink required,

$$
R_{t h, H S}=\frac{\left(T_{H S}-T_{A}\right)}{\sum_{i=1}^{8} P_{\text {loss }, i}} \ldots \ldots \ldots \ldots \ldots \ldots \ldots \ldots \ldots
$$

The volume of the heatsink is obtained from the Cooling System Performance Index (CSPI) as per the equation,

$$
V_{H S}=\frac{1}{C S P I \cdot R_{t h, H S}}
$$

Considering a forced air cooling system, CSPI $=10$ $\mathrm{KW} K^{-1} m^{-3(12)}$.

Aluminium make heatsink is considered to realise low weight.

2.5 Design of Link Capacitors The power at the output of CHB consists of constant DC component demanded by the load and a pulsating component at twice the network frequency. This fluctuating component is purely reactive and is absorbed by the bus capacitors giving rise to the fluctuation. The capacitors are sized appropriately to limit harmonics and to assure minimum ripples in the DC bus $(\leq 5 \%)$. The instantaneous power equation for the $\mathrm{CHB}$ :

$$
V_{s}(t) I_{s}(t)=L . I_{s} \cdot \frac{d I_{s}}{d t}+N \cdot C_{1} \cdot V_{c} \frac{d V_{c}}{d t}+P_{\text {load }} \cdots \cdots
$$

With unity power factor operation, the equation can be solved for

$$
\begin{aligned}
V_{c}(t) & =\sqrt{V_{c 0}^{2}+\frac{V_{c p k} \cdot I_{s p k} \cdot \cos (2 \omega \cdot t-\phi)}{2 \cdot \omega \cdot N \cdot C_{1}}} \\
& \approx V_{c 0}+\frac{V_{c p k} \cdot I_{s p k} \cdot \cos (2 \omega \cdot t-\phi)}{4 \cdot \omega \cdot N \cdot C_{1} \cdot V_{c 0}} \cdots
\end{aligned}
$$

where $V_{c 0}=$ steady state average value of the cell voltage. Hence the peak-peak ripple voltage and the capacitance required is given by:

$$
\Delta V_{c p p}=\frac{V_{c p k} \cdot I_{s p k}}{2 \omega \cdot N \cdot V_{c 0} \cdot C_{1}} ; C_{1} \geq \frac{V_{c p k} \cdot I_{s p k}}{2 \omega \cdot N \cdot V_{c 0} \cdot \Delta V_{c p p}} \cdots \cdots
$$

Among the existing capacitor technologies (Multi-layer ceramic, Al Electrolytic, polymer film), polymer film capacitors shows the greatest flexibility towards device geometry desirable for space optimization in a traction system. The preferred film material is polypropylene which allows a continuous operating temperature of $100^{\circ} \mathrm{C}$. The dielectric dissipation factor is low (DDF $=0.0002)$. The density is also low, $0.91 \mathrm{gcm}^{-3}$.

The capacitor volume is then estimated from the capacitance value and the dc voltage by assuming a constant volume per stored energy of $6.3 \mathrm{~cm}^{3} / \mathrm{J}$, which has been found by averaging the datasheet values of foil capacitors of various capacitance and voltage ratings $(600 \mathrm{~V}$ to $1300 \mathrm{~V})$, and from different manufacturers ${ }^{(13)}$.

2.6 Variation of Efficiency and Power Density of Primary Stage with Frequency The losses are dominated by the device's losses. The conduction losses remain constant but the switching losses increases proportionately [Fig. 4(a)]. Hence the volume of heat-sink required to dissipate the device's losses increases. The reactor losses mainly include the ohmic losses which decrease with the decrease in size with increase in frequency. The volumetric power density reaches the maxima of $5.03 \mathrm{KW} / \mathrm{L}$ at frequency of $3 \mathrm{kHz}$ while the weight power density reaches its maxima of $3.23 \mathrm{KW} / \mathrm{KG}$ at $4.1 \mathrm{kHz}$ [Fig. 4(b)]. Since the weight actually aids adhesion in traction, the optimization criteria is maximization of volumetric power density. Hence the parameters corresponding to $3 \mathrm{kHz}$ are selected for the primary stage $\mathrm{CHB}$. The corresponding reactor required is $23.96 \mathrm{mH}$. The efficiency realised is $99.54 \%$ with a nominal weight of $1307 \mathrm{KG}$ and volume of 822L. The component-wise weight and loss details are given in Tables 1 and 2 respectively.

\section{Secondary Stage Design: DC/DC Converter with MFT}

3.1 Selection of Configuration and Modulation of DC/DC Converter The design primary stage yields the 


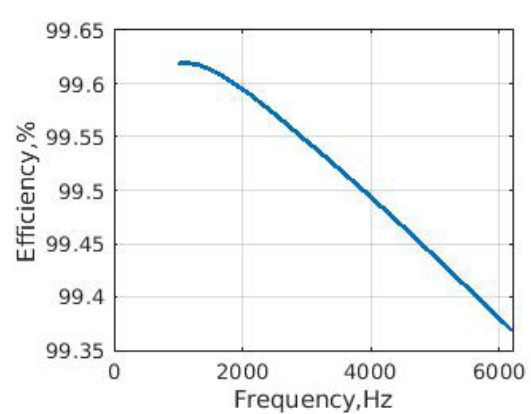

(a) Efficiency, $\eta$ vs frequency

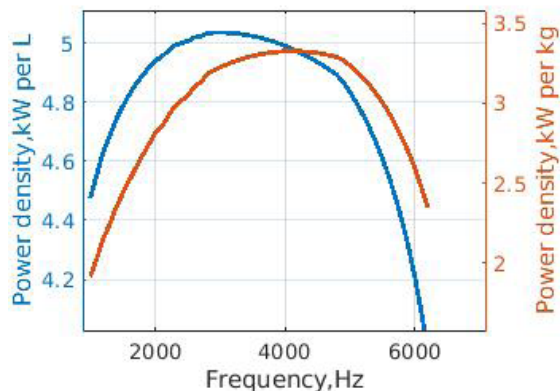

(b) Power density, $\rho$ vs frequency

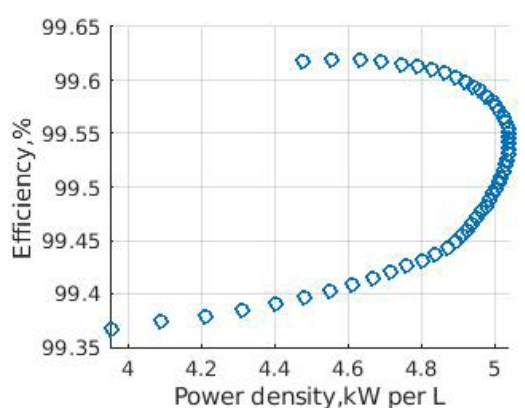

(c) $\eta-\rho$ pareto-front of $\mathrm{CHB}$

Fig. 4. Variation of efficiency and power-density of Primary Stage with switching frequency

Table 1. Weight components of primary stage

\begin{tabular}{c|c|c|c|c} 
Component & Volume, $d m^{3}$ & Weight, kg & Volume, \% & Weight, \% \\
\hline Reactor & 73.08 & 505.31 & 8.89 & 38.65 \\
Heat sink & 54.9 & 148.22 & 6.68 & 11.34 \\
Link capacitor & 694 & 631.65 & 84.43 & 48.32 \\
Devices & NIL & 22 & NA & 1.68 \\
\hline
\end{tabular}

Table 2. Loss components of primary stage

\begin{tabular}{c|c|c} 
Component & Loss, KW & Loss, \% \\
\hline Device's conduction & 8.71 & 46.1 \\
Device's switching & 8.03 & 42.5 \\
Reactor core & 0.04 & .2 \\
Reactor ohmic & 2.12 & 11.21 \\
\hline
\end{tabular}

input voltage $(=3.83 \mathrm{KV})$ and power $(=378.2 \mathrm{KVA})$ to be handled by each module of DC/DC converter. The first step in the design of secondary stage is the selection of converter topology among DAB/SRC and the modulation strategy of the full-bridges at both sides of the isolation. In (14), a comparison of efficiencies of four topologies for isolated bidirectional DC/DC converter is done for a specification. The topologies are Dual Active Bridge (DAB) and Series Resonant Converter (SRC)-with and without a boost stage. In this paper, DAB and SRC topologies have been investigated in detail without the boost stage as it will increase the device count and also demand additional space which will be significant for an $\mathrm{N}$ module PET. The dual active bridge converter [Fig. 5(a)) utilizes the leakage inductance L as a buck or boost inductor to transfer power over a wide range in both directions. Adding a capacitor in series to the leakage inductance leads to the series resonant converter [Fig. 5(c)] which can also be operated with bi-directional power flow within a wide range of input and output voltages. The selection of the topology is done on the basis of least device losses which is the sum of conduction and switching losses. The latter is controlled through optimum modulation strategy. The conventional rectangular operation mode with $50 \%$ duty ratios of the primary and the secondary transformer voltages is not considered as the ZVS exists over a narrow region of phase shift of the voltages and the switching currents can not be controlled. The triangular and trapezoidal mode of modulation results in lower switching losses. However as the triangular current mode has a low power transfer capability, the trapezoidal current mode of modulation [Fig. 5(b)] is considered for the design of DAB. With this ZCS at primary and combined ZVS/ZCS is achieved in the secondary. The devices suitable for both sides are $6.5 \mathrm{KV}$ and $3.3 \mathrm{KV}$ for a blocking voltage utilization of $58 \%$. The current ratings are
$250 \mathrm{~A}$ and 400 A respectively. The turns ratio for both should satisfy the constraint:

$$
n \leq \frac{V_{1 \min }}{V_{2 \max }}
$$

For DAB, the value of leakage inductance, $\mathrm{L}$ is limited by the maximum power:

$$
L \leq \frac{\left(n \cdot V_{1 \min } \cdot V_{2 \min }\right)^{2}}{4 \cdot f_{s} . P .\left(V_{1 \min }{ }^{2}+n \cdot V_{1 \min } \cdot V_{2 \min }+V_{2 \min }{ }^{2}\right)} \cdots
$$

The steady state voltage and current waveforms for the trapezoidal current mode modulation of a DAB is shown in [Fig. 5(b)]. The time durations $T_{1}, T_{2}, T_{3}$ to power transfer $\mathrm{P}$ at frequency $\mathrm{f}$ are given by:

$$
\begin{aligned}
& T_{1}=\frac{n \cdot V_{2}-V_{1}+2 V_{1} \frac{\phi}{\pi}}{2 \cdot f_{s} \cdot\left(V_{1}+n \cdot V_{2}\right)} ; T_{2}=\frac{1-\frac{2 \phi}{\pi}}{2 \cdot f_{s}} ; T_{3}=\frac{V_{1}-n \cdot V_{2}+2 n \cdot V_{2} \frac{\phi}{\pi}}{2 f_{s} \cdot\left(V_{1}+n \cdot V_{2}\right)} \\
& \text {.................... (32) } \\
& \phi=\frac{\frac{\pi}{2} \cdot \operatorname{sign}(P)\left\{V_{1}^{2}+\left(n \cdot V_{2}\right)^{2}-\left(n \cdot V_{2}+V_{1}\right)\left[n \cdot V_{1} \cdot V_{2} \cdot(1-\lambda)\right]^{\frac{1}{2}}\right\}}{\left\{V_{1}^{2}+\left(n \cdot V_{2}\right)^{2}+n \cdot V_{1} \cdot V_{2}\right\}} \\
& \text {.................... (33) } \\
& \lambda=\frac{4 \cdot f_{s} \cdot L \cdot P \cdot\left\{V_{1}^{2}+n \cdot V_{1} \cdot V_{2}+\left(n \cdot V_{1} \cdot V_{2}\right)^{2}\right\}}{\left(n \cdot V_{1} \cdot V_{2}\right)^{2}}
\end{aligned}
$$

The equations above enables a search for the possible combination of $\mathrm{n}$ and $\mathrm{L}$ for which the converter has least device losses at full load at a specified frequency. The loss curve at full load for a frequency of $2 \mathrm{kHz}$ is shown in [Fig. 6(a)]

(a) Increase in turns ratio, $n$ decreases the tank current and hence losses.

(b) For any n, there is a value of leakage inductance, $\mathrm{L}$ at which the switching loss (sum of switching losses at two instants within a half period) achieves a minimum value.

The modulation for SRC is similar to triangular current mode for $\mathrm{DAB}{ }^{(15)}$ where the durations $T_{1}$ and $T_{2}$ are controlled for a given power flow to minimize device losses by ensuring zero crossings of the current at switching instants. The direction of power flow is reversed when the durations are transposed. There is an idle duration $T_{3}=0.5 T-\left(T_{1}+T_{2}\right)$ at low power, when power transferred is zero. This is possible if the voltage across the resonant capacitor does not forward biases the diode in either bridge when the current goes through zero in a half cycle. This serves as a design constraint which gives rise to lower number of valid designs. The resonant frequency, $\omega_{r}$ is selected between $80-90 \%$ of the selected frequency. The durations $T_{1}$ and $T_{2}$ for the modulation 


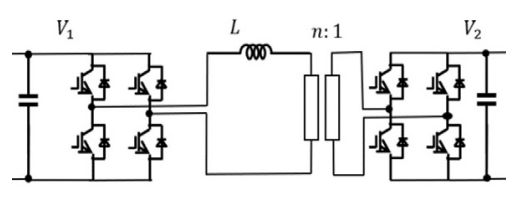

(a) Dual Active Bridge DC/DC Converter

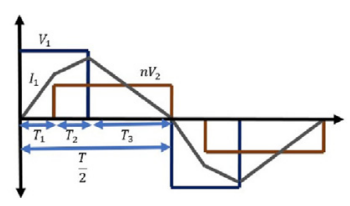

(b) Traezoidal Current Mode Modulation of DAB

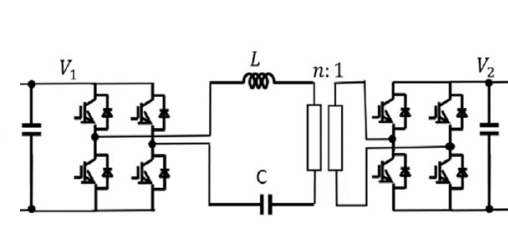

(c) Series Resonant DC/DC Converter

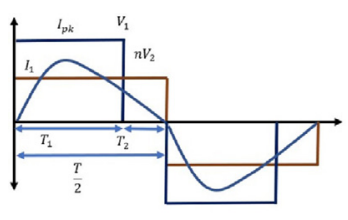

(d) Clamped Mode Current Modulation of SRC

Fig. 5. DC/DC Converter configurations and Modulation modes under consideration

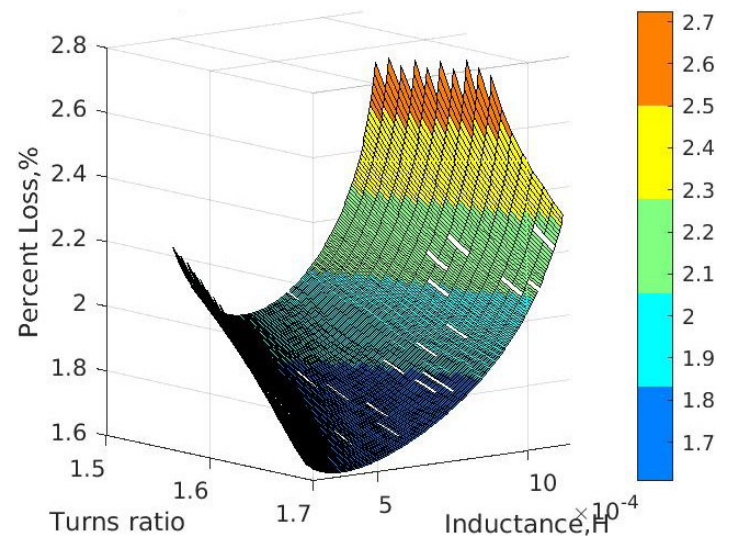

(a) Loss curve of DAB at $\mathrm{f}=2 \mathrm{kHz}$

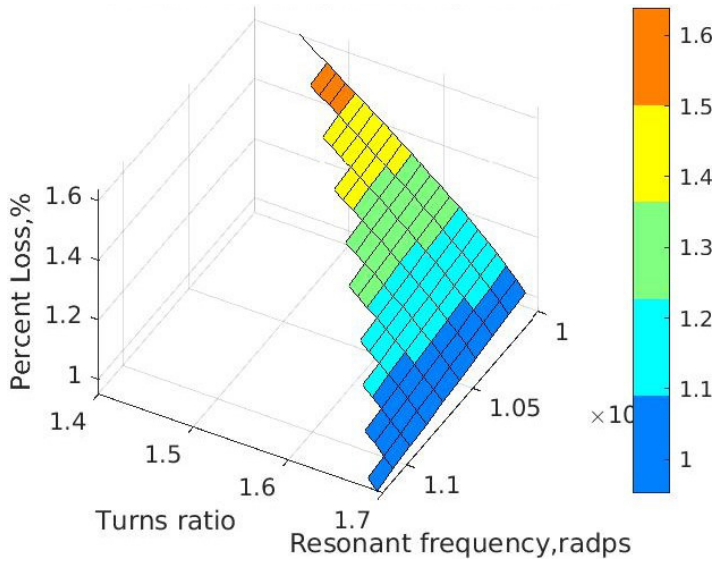

(b) Loss curve of SRC at $\mathrm{f}=2 \mathrm{kHz}$

Fig. 6. Loss surface of the DAB and SRC converters

of SRC shown in [Fig. 5(d)] are given by:

$T_{1}=\frac{1}{\omega_{r}} \cdot \cos ^{-1}\left(\frac{r_{1}^{2}+V_{1}^{2}-r_{2}^{2}}{2 \cdot r_{1} \cdot V_{1}}\right) ; T_{2}=\frac{1}{\omega_{r}} \cdot \cos ^{-1}\left(\frac{r_{2}^{2}+V_{1}^{2}-r_{1}^{2}}{2 \cdot r_{2} \cdot V_{1}}\right)$ .................... (35)

$r_{1}=\left|V_{c o}\right|+V_{1}-n \cdot V_{2} ; r_{2}=\left|V_{c o}\right|+n \cdot V_{2}$

where $\left|V_{c o}\right|$ is the peak voltage across the resonant capacitor corresponding to power $\mathrm{P}$ which is given by:

$$
P=\frac{4 \cdot n \cdot V_{2} \cdot\left|V_{c o}\right| \cdot f_{s}}{\omega_{r} \cdot z_{o}} ; f_{s}=\frac{1}{2\left(T_{1}+T_{2}+T_{3}\right)} \cdots \cdots
$$

Design algorithm steps:

1 . For $n \leq n_{\max }$ find $\left|V_{c o}\right|$, the peak value of the voltage across the resonant capacitor for power $\mathrm{P}$ deploying the above equations.

2. If $\left|V_{c o}\right|>n . V_{2 \min }$ goto step 1 to alter parameter else go to step 3.

3. Find resonant impedence $z_{o}$ and calculate the pulse durations followed by the device losses.

The loss curve for SRC at $\mathrm{f}=2 \mathrm{kHz}$ on full load is shown in [Fig. 6(b)].

(a) Increase in n decreases the tank current, hence the losses.

(b) Increase in resonant frequency decreases the switched current for any $\mathrm{n}$ and hence the switching losses decreases.

Hence the least losses are realised with maximum value of $\mathrm{n}$ and $\omega_{r}$ for any $\mathrm{f}$. For the considered design, the SRC delivers lower losses than the DAB for any frequency. Hence SRC configuration in the clamped mode of modulation has been considered for secondary stage.

3.2 Cooling System Design for Converter Power Modules As most of the device losses occur in the form of switching losses, the devices which are switched suffer the major portion of losses. In traction mode, the devices $S_{2}, S_{4}$ of the primary bridge of SRC are switched off every half cycle and they suffer the most losses. Forced air cooling with module mounted heat sinks is not able to dissipate the device heat. Hence direct water cooling of heat-sinks mounted on base plates of each module with 16 devices of both bridges is considered. The flow rate is maintained to keep the water temperature, $T_{F}$ at $25^{\circ} \mathrm{C}$. The thermal resistance of heat-sink required is calculated in a similar fashion to $\mathrm{CHB}$ modules:

$$
T_{H S, \max }=\min _{i}\left(T_{j}-P_{\text {loss }, i} \cdot R_{t h, J H i}\right) ; R_{t h, H S}=\frac{\left(T_{H S, \max }-T_{F}\right)}{\sum_{i=1}^{16} P_{\text {loss }, i}}
$$

The volume of cooling system (excluding pumps, exchanger, pipes etc.) is calculated using CSPI $=270 \mathrm{~W} K^{-1} L^{-1}$ typical for a water cooled system.

3.3 Size of Secondary Side Link Capacitors The power transferred to the secondary winding consists of DC component and components at frequencies $(4 \mathrm{k}-2) \mathrm{f}$ where $\mathrm{k}=$ $1,2,3$. . with decreasing order of magnitudes. The dominant ripple in the power is contributed by the double frequency component and hence the filter capacitor can be designed to limit the same within 5\% and multiplying it by a factor of 1.2 to account for the other harmonics.

$$
C_{2} \geq \frac{P_{a v g}}{\omega_{s} \Delta V_{2 p p} . V_{2 s s}}
$$

Similar to primary stage, the capacitors of secondary stage are also of polypropylene film type.

3.4 Design of the Medium Frequency Transformer

The set of optimal parameters for the converter designed viz. the turns ratio, leakage inductance and the rms input current serves as the design specifications for the MFT. The secondary voltage is fixed by the DC link of drive which is 

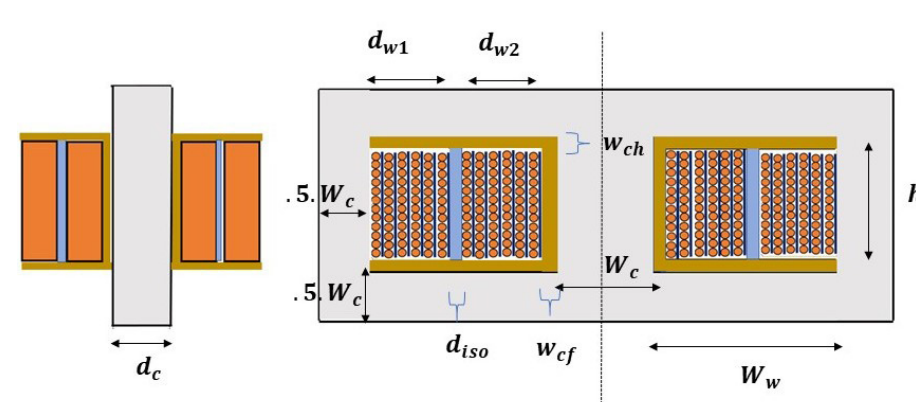

(a) MFT cross sectional view with heat-sinks mounting
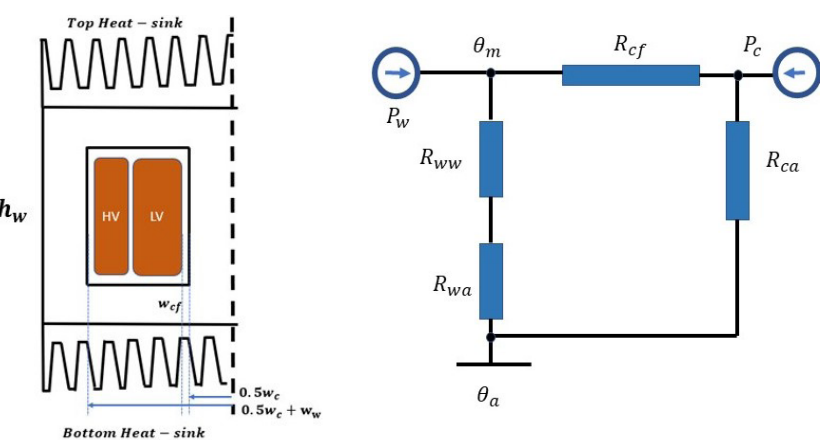

(b) Simplified thermal model of the MFT

Fig. 7. MFT Model

1.9 KV here. As the leakage inductance serves as the parameter of the tank circuit, precision in the same is desired. The core shape doesn't contribute to the optimization hence its chosen independently. EE Type core is chosen as it offers advantages of easy assembling and suitable for concentric winding as the leakage inductance has to be accurately matched with high precision. Other independent parameters being:

1. Core material: Available choices for high frequency areFerrite, Nanocrystalline and Amorphous Iron. Amorphous iron-2605SA1 is chosen as it offers the dual advantage of high flux density $\left(B_{\text {sat }}=1.56 \mathrm{~T}\right)$ and low losses (specific loss $=1.37 \mathrm{Wm}^{-3}$ ) and its cheaper compared to nanocrstalline.

2. Winding type and material: Available choices for high frequency- Litz and foil type, material-Copper or Aluminium, construction-solid or hollow. Copper Litz winding is chosen as the dual selection of gauge and strands makes it easier to optimize the window utilization as well as the skin effect losses at high frequency.

3. Isolation Material: MICARES 720, an FeCrAl alloy having dielectric strength $=25 \mathrm{KVmm}^{-1}$ is chosen for the design. For the recommended isolation of $30 \mathrm{KV}$ the minimum thickness required for the dielectric is given by:

$$
d_{\text {iso }} \geq \frac{V_{\text {iso }}}{v \cdot E_{\text {ins }}}=\frac{30 \mathrm{KV}}{0.45 \times 25 \mathrm{KVmm}}=2.7 \mathrm{~mm} \cdots
$$

A safety factor $v$ of $45 \%$ is considered. This isolation thickness serves dual purpose of providing the isolation to the windings and also match the leakage inductance with the desired value.

4. Coil former material: CoolPoly D5108, a thermally conducting plastic having high electric strength is chosen.

The variables used for optimizing the MFT design are:

1. Core dimensions: $\left[w_{w}, h_{w}, d_{c}, w_{c}\right]=\left[c_{1}, c_{2}, c_{3}, 1\right] w_{c}$ where $c_{1} \in[0.2,2], c_{2} \in[1,4], c_{3} \in[1,6]$ and the ratio of windowwidth allotted to the windings: $\alpha \in[0.4,0.6]$ [Fig. 7(a)]

2. Litz winding parameters: AWG between 30 to 40 with variable number of strands.

The constraints for the design are:

1. The insulation thickness provides the isolation and matches the leakage inductance.

2. Integral number of turns resulting in an error of less than $1 \%$ in turns ratio. 3. Window utilisation for both the windings is atleast $25 \%$

4. The hotspot temperature which is the temperature of LV winding placed near to the core is less than $110^{\circ} \mathrm{C}$.

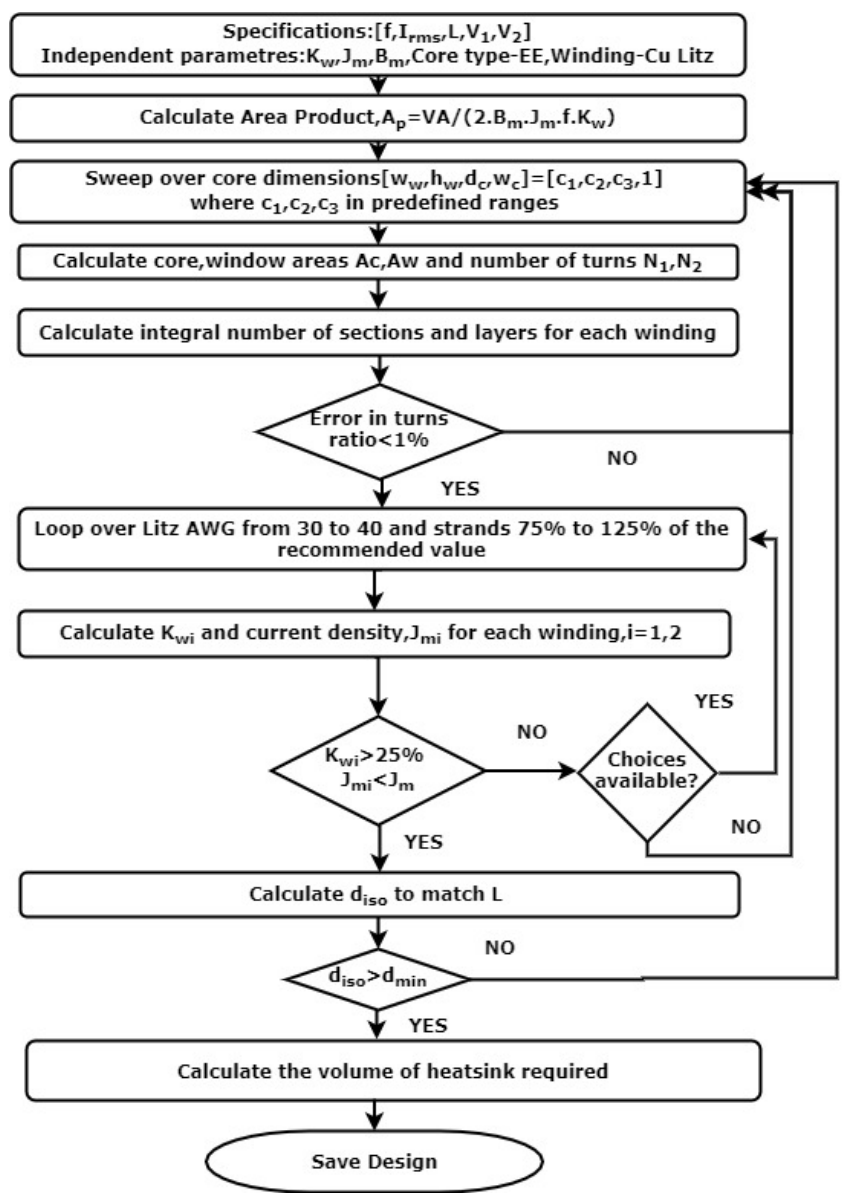

Fig. 8. MFT Design Algorithm

5. The current density in both the windings does not exceed the specified value.

Among multiple valid designs generated by the algorithm, [Fig. 8] the one with minimum volume is selected. The guidelines given in (16) is followed to fill the winding optimally with litz winding having AWG and strands resulting in least high-frequency skin effect losses. Keeping the economy of manufacturing in mind, litz with AWG between 30 to 40 is considered only and strands from $75 \%$ to $125 \%$ of the recommended number of strands. The AC resistance factor is calculated as

$$
F_{R}=\frac{R_{a c}}{R_{d c}}=1+\frac{\left(\pi \cdot n_{s} \cdot N\right)^{2} \cdot d_{s}^{6}}{192 \cdot \delta^{4} \cdot h_{w}^{2}}
$$




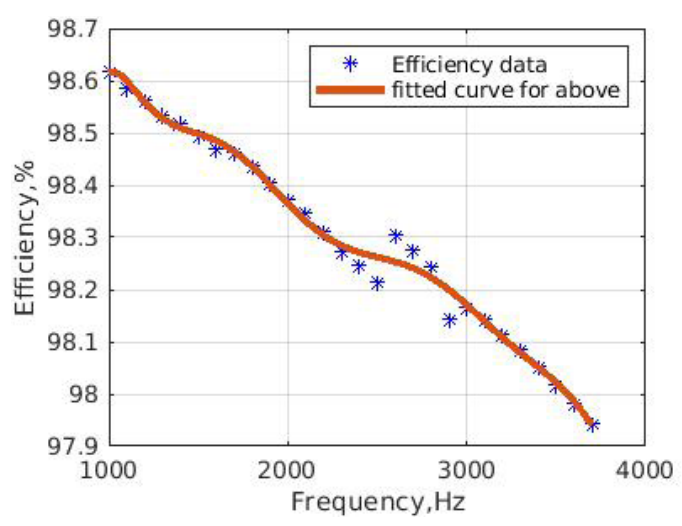

(a) Efficiency, $\eta$ vs frequency

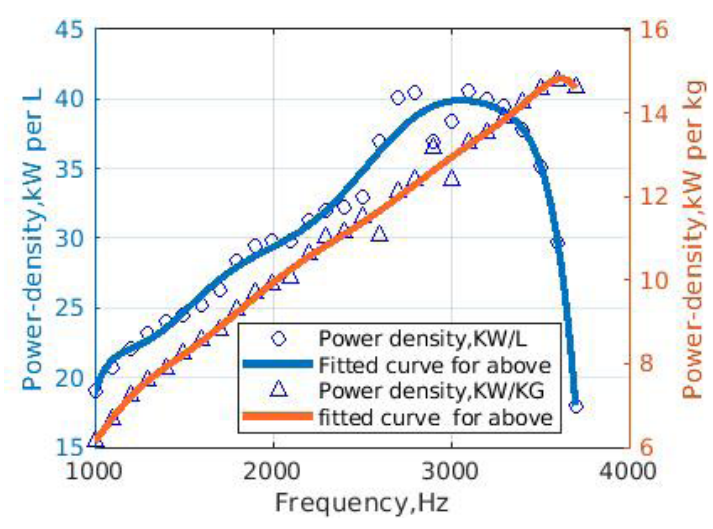

(b) Power density, $\rho$ vs frequency

Fig. 9. Efficiency and power density variation of the optimized secondary stage with frequency

Where $n_{s}, d_{s}, \mathrm{~N}$ are the number $\&$ diameter of strands and winding turns respectively. $\delta$ is the skin depth and $h_{w}$ is the winding breadth. Dowell's model is used to calculate the leakage inductance and high frequency winding losses to a reasonable accuracy.

$$
\begin{aligned}
L_{\sigma} & =\frac{N_{1}^{2} \mu_{o} \cdot L_{w}}{H_{w}}\left[\frac{d_{w 1} m_{w 1}}{3} \cdot F_{w 1}+\frac{d_{w 2} m_{w 2}}{3} \cdot F_{w 2}+d_{i s o}\right. \\
& \left.+\frac{d_{w 1} \cdot\left(m_{w 1}-1\right)\left(2 \cdot m_{w 1}-1\right)}{6 \cdot m_{w 1}}+\frac{d_{w 2} \cdot\left(m_{w 2}-1\right)\left(2 \cdot m_{w 2}-1\right)}{6 \cdot m_{w 2}}\right]
\end{aligned}
$$$$
\text { .................... (42) }
$$

$F_{w}=\frac{1}{2 . m^{2} \cdot \delta} \cdot\left[\left(4 . m^{2}-1\right) \phi_{1}-2 .\left(m^{2}-1\right) \phi_{2}\right] \ldots \ldots \ldots$

$\phi_{1}=\frac{\sinh (2 \Delta)-\sin (2 \Delta)}{\cosh (2 \Delta)+\cos (2 \Delta)} ; \phi_{2}=\frac{\sinh (\Delta)-\sin (\Delta)}{\cosh (\Delta)+\cos (\Delta)} \ldots$

$\Delta=\frac{d_{e q}}{\delta} ; \delta=\frac{1}{\sqrt{\pi \cdot \mu_{o} . \sigma \eta \cdot f}}$

$\mathrm{m}=$ Number of winding layers The HF core losses are calculated by the Steinmetz equation:

$P_{\text {core }}=k_{i} \cdot V_{M F T} \cdot f \cdot \int_{0}^{T}\left|\frac{d B}{d t}\right|^{\alpha}(\Delta B)^{\beta-\alpha} d t=k_{i} \cdot V_{M F T} \cdot 2^{\alpha+\beta} \cdot B_{m}^{\beta} f^{\alpha}$

Forced air cooling of the MFT is considered with two heatsinks mounted on the top and bottom [Fig. 7(a)]. A detailed thermal model based on all modes of heat dissipation with additional forced air cooled heatsinks mounted at the top and bottom surfaces is considered [Fig. 7(b)]. The thermal resistance of the core is neglected as the thermal conductivity is very high. In this model the highest temperature reached is at the LV winding in contact with the core ${ }^{(17)}$. The temperature rise can be given by:

$$
\Delta \theta=\left(\frac{R_{c a} P_{c}+\left(R_{c f}+R_{c a}\right) P_{w}}{R_{c a}+R_{c f}+R_{w w}+R_{w a}}\right)\left(R_{w a}+R_{w w}\right) \cdots \cdots
$$

where $P_{w}, P_{c}$ are the winding and core losses respectively and $R_{w w}, R_{w a}, R_{c a}, R_{c f}, R_{c w}$ are the thermal resistances betweenboth windings, winding to ambient, core to ambient, core to former, core to winding respectively. The ambient temperature considered is $50^{\circ} \mathrm{C}$ and the thermal resistance of heatsink required is calculated for maximum rise of $60^{\circ} \mathrm{C}$.
Table 3. Loss components of secondary stage per module

\begin{tabular}{c|c|c} 
Component & Loss, KW & Loss, \% \\
\hline Device's conduction & 1.53 & 21.75 \\
Device's switching & 3.9 & 55.5 \\
MFT core & 0.65 & 9.2 \\
MFT ohmic & 0.953 & 13.6 \\
\hline
\end{tabular}

Table 4. Weight distribution of secondary stage per module

\begin{tabular}{c|c|c|c|c}
\hline Component & Volume, $\mathrm{dm}^{3}$ & Weight, kg & Volume, \% & Weight, \% \\
\hline Heat sink & 1.135 & 3.07 & 12.42 & 8.8 \\
Devices & NIL & 4 & NA & 11.43 \\
Link capacitor & 1.47 & 1.34 & 16.1 & 3.81 \\
MFT & 6.53 & 26.6 & 71.5 & 76 \\
\hline
\end{tabular}

Table 5. MFT parameters

\begin{tabular}{c|c} 
Parameter & Value \\
\hline$\left[V_{1}, V_{2}\right], \mathrm{KV}$ & {$[3.21,1.9]$} \\
Turns ratio & 1.69 \\
Frequency,kHz & 3.1 \\
Leakage inductance, $\mu \mathrm{H}$ & 977 \\
Number of turns $N_{1}, N_{2}$ & 42,25 \\
Primary Winding $\left[n_{s 1}, d_{s 1}(\mathrm{~mm})\right]$ & {$[1019,0.143]$} \\
Secondary Winding $\left[n_{s 2}, d_{s 2}(\mathrm{~mm})\right]$ & {$[1725,0.143]$} \\
Dimensions $\left[h_{w}, w_{c}, w_{w}, d_{c}\right], \mathrm{cm}$ & {$[5.2,4.72,9.34,10.4]$} \\
Window factors, $k_{w 1}, k_{w 2}$ & $30.8 \%, 26.4 \%$ \\
$d_{i s o}, \mathrm{~mm}$ & 4.53 \\
\hline
\end{tabular}

\subsection{Variation of Efficiency and Power-density of Sec-} ondary Stage with Frequency The device losses contribute to the dominant portion of total losses which increase with frequency [Fig.9(a)] requiring large size of the water cooled heat-sink. The size of the MFT and the capacitor decreases with increase in frequency. Hence the efficiency decreases monotonically with frequency but the volumetric power density reaches maxima of $40.64 \mathrm{KW} / \mathrm{L}$ at frequency of $3.1 \mathrm{kHz}$ [Fig. 9(b)]. The efficiency realised is $98.14 \%$. The SRC and MFT parametres at this frequency are selected as the optimum set.

\section{Results and Conclusion}

The PET design is realised by separate design of the power stages. The efficiency and power-density of each stage is analysed with respect to the topology, modulation strategy, converter circuit parameters and the magnetics corresponding to a range of switching frequencies. The efficiency of the realised PET is $97.7 \%$ which is significantly higher than the LFT system where the transformer's efficiency alone is $97 \%$. 
The weight of all the components of both the power stages is 1.69 Tonnes whereas the transformer in the conventional system alone weighs 3.1 Tonnes. The methodology in general can be applied to design a substitute PET for any low frequency system. The loss and volumetric dominant components shed important design considerations to make PET more attractive. About $79.5 \%$ of the total losses are device losses which demand high volume of the cooling heat-sinks or more sophisticated cooling methods like Direct Liquid Cooling (DLC)/Double Surface Cooling (DSC) which adds cost to the system. A cost effective comparison between using $\mathrm{SiC}$ based devices and better cooling methods may be carried out. The capacitors in CHB occupy about $84.4 \%$ of the total volume as the existing technologies restrict their energy storage density. High epsilon film capacitors can be explored

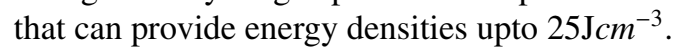

\section{References}

( 1 ) J. Feng, W.Q. Chu, Z. Zhang, and Z.Q. Zhu: "Power Electronic TransformerBased Railway Traction Systems: Challenges and Opportunities", in IEEE Journal of Emerging and Selected Topics in Power Electronics, Vol.5, No.3 (2017)

( 2 ) D. Dujic, F. Kieferndorf, and F. Canales: "Power Electronics Transformer Technology for Traction Applications-An Overview", in Conference on Power Conversion and Intelligent Motion (PCIM), Nuremberg (2011)

( 3 ) B. Engel, M. Victor, G. Bachmann, and A. Falk: " 15 kV/16.7 Hz Energy Supply System with Medium Frequency Transformer and 6.5 kV IGBTs in Resonant Operation", in European Conference on Power Electronics and Applications (EPE), Toulouse, pp.2-4 (2003)

( 4 ) J. Taufiq: "Power Electronics Technologies for Railway Vehicles", in Power Conversion Conference (PCC), Nagoya, pp.1388-1393 (2007)

( 5 ) D. Dujic, A. Mester, T. Chaudhuri, A. Coccia, F. Canales, and J.K. Steinke: "Laboratory scale prototype of a power electronic transformer for traction applications", in Proc. Eur. Conf. Power Electron. Appl. (EPE), pp.1-10 (2011)

( 6 ) D. Dujic, F. Kieferndorf, F. Canales, and U. Drofenik: "Power electronic traction transformer technology", in Proc. Int. Power Electron. Motion Control Conf. (IPEMC), Harbin, China, pp.636-642 (2012)

( 7 ) L. Heinemann: "An Actively Cooled High-Power, High Frequency Transformer with High Insulation Capability", in IEEE Applied Power Electronics Conference and Exposition (APEC), Dallas, pp.352-357 (2002)

( 8 ) H. Hoffmann and B. Piepenbreier: "High Voltage IGBTs and Medium Frequency Transformer in DC-DC Converters for Railway Applications", in Symposium on Power Electronics, Electrical Drives, Automation and Motion (SPEEDAM), Pisa, pp.744-749 (2010)

( 9 ) H. Iman-Eini, Sh. Farhangi, J.-L. Schanen, and J. Aime: "Design of Power Electronic Transformer based on Cascaded H-bridge Multilevel Converter", IEEE International Symposium on Industrial Electronics (2007)

(10) J. Biela and J.W. Kolar: "Cooling concepts for high power density magnetic devices", in Proc. Power Convers. Conf. (PCC), Nagoya, Japan, pp.1-8 (2007)

(11) K. Venkatachalam, C.R. Sullivan, T. Abdallah, and H. Tacca: "Accurate Prediction of Ferrite Core Loss with Nonsinusoidal Waveforms Using Only Steinmetz", IEEE Workshop on Computers in Power Electronics

(12) U. Drofenik, G. Laimer, and J.W. Kolar: "Theoretical converter powerdensity limits for forced convection cooling", in Proc. 26th Int. Conf. Power Electron., Intell. Motion, Power Quality (PCIM), Nuremberg, Germany, pp.608-619 (2005)

(13) M. März, A. Schletz, B. Eckardt, S. Egelkraut, and H. Rauh: "Power electronics system integration for electric and hybrid vehicles", in Proc. 6th Int. Conf. Integr. Power Syst. Conf. (CIPS), Nuremberg, Germany, pp.16-18 (2010)

(14) F. Krismer, J. Beila, and J.W. Kolar: "A comparative evaluation of isolated bi-drectional DC/DC Converters with wide input and output voltage range", Conf. Rec. of the IEEE 40th Annual Industry Applications Conference IAS 2005, Hong Kong, China, pp.599-606 (2005)

(15) A. Hillers, D. Christen, and J. Biela: "Design of a highly efficient Isolated bidirectional LLC resonant converter", 15th International Power Electronics and Motion Control Conference, EPE-PEMC 2012 ECCE Europe, Novi Sad, Serbia.

(16) C.R. Sullivan and R.Y. Zhang: "Simplified design Metod for litz wire", In
IEEE Applied Power Electronics Conference (APEC), pp.2667-2674 (2014)

(17) R. Petkov: "Optimum Design of a High power high frequency transformer", in IEEE Transactions in Power Electronics Vol.11, No.1 (1996)

\section{Appendix}

\section{Appendix-I}

The average current in Kth region:

$$
\left(I_{s}\right)_{K}=\frac{1}{\Delta t_{K}} \int_{t_{K-1}}^{t_{K}} I_{s p k} \cdot \sin (\omega \cdot t) d t=I_{s p k} \frac{\cos \left(\omega \cdot t_{K-1}\right)-\cos \left(\omega \cdot t_{K}\right)}{\omega\left(t_{K}-t_{K-1}\right)}
$$

The average current in Kth region in PWM mode:

$$
\begin{aligned}
\left(I_{s P W M}\right)_{K}= & \frac{1}{\Delta t_{K}} \int_{t_{K-1}}^{t_{K}} I_{s p k} \cdot \sin (\omega \cdot t) \cdot D(t) d t=-(K-1)\left(I_{s}\right)_{K} \\
& +\frac{V_{r p} \cdot I_{s p}}{2 \cdot V_{c}}\left[1-\frac{\sin \left(2 \omega t_{K}\right)-\sin \left(2 \omega t_{K-1}\right)}{2 \cdot \omega \Delta t_{K}}\right]
\end{aligned}
$$

\section{Appendix-II}

The low frequency and high frequency core losses $\left(P_{c L F}, P_{c H F}\right)$ in the reactor given by i-GSE:

$$
\begin{aligned}
& P_{c L F}=k_{i} \cdot V_{\text {core }} \cdot f_{g}^{\alpha} \cdot B_{m}^{\beta} \ldots \ldots \ldots \ldots \ldots \ldots \ldots \ldots \ldots \ldots \ldots \ldots \\
& P_{c H F}=V_{\text {core }} \cdot f_{g} \cdot \sum_{j} k_{j} \cdot\left|\frac{1}{\Delta T_{j}^{\alpha}} \cdot\right|\left|\Delta B_{j}^{\beta}\right| .
\end{aligned}
$$

where $k_{i}, \alpha, \beta$ are the Steinmetz parameters for the core, $f_{g}$ is the catenary frequency and $V_{c}$ is the volume of the core. $k_{i}$ is computed from the specific core loss constant $\mathrm{k}$.

$$
k_{i}=\frac{k}{2^{\beta+1} \cdot \pi^{\alpha-1} \cdot\left(.2761+\frac{1.7061}{\alpha+1.354}\right)} \cdots \cdots \cdots \cdots \cdots
$$

where $\Delta B_{j}$ is the peak to peak flux density swings of the piecewise HF linear flux segments and $\Delta T_{j}$ is the corresponding time period such that $\sum_{j} \Delta T_{j}=\frac{1}{f_{q}}$. For accurate computation of the HF core losses, $\left(k_{j}, \alpha_{j}, \beta_{j}\right)$ are supposed to be taken from the loss map of the core material due to their dependency on the premagnetization state. In this paper the same set of Steinmetz parameters have been used for the computation of both the losses as the reactor losses contribute to a small fraction of the overall losses of the primary stage $\mathrm{CHB}$ converter and hence the error in achieving the optimal set of parameters is negligible. Hence the HF core loss computation equation is modified as:

$$
\begin{array}{r}
P_{c H F}=V_{c} \cdot k_{i} \cdot f_{g} \cdot \sum_{j}\left[\left|\frac{1}{\Delta T_{o n}}\right|^{\alpha-\beta+1} \cdot \frac{\left|(k+1) V_{c}-V_{s}\right|^{\beta}}{\left(N . A_{c}\right)^{\beta}}\right. \\
\left.\left.+\left|\frac{1}{\Delta T_{\text {off }}}\right|^{\alpha-\beta+1} \cdot \frac{\mid\left(V_{s}-\left.k \cdot V_{c}\right|^{\beta}\right.}{\left(N . A_{c}\right)^{\beta}}\right] \cdots \cdots \text { (A } 6\right)
\end{array}
$$

Sandeep Kumar Chowdhury (Non-member) received B.E. from De-

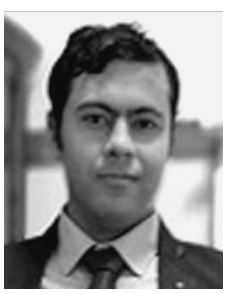
partment of Electrical Engg. Jadavpur University, Kolkata in 2010. He has been working with Indian Railways as an IRSEE cadre Officer from 2012 and is currently Masters student in Waseda University. His research interests include optimum design, control of power converters and motor drives in traction applications. 
Hiroyasu Kobayashi (Member) received M.E. and Dr. Eng. from (a) Electrical and Electronics Engineering Course, Graduate School of Engineering, Chiba University in 2016 and 2019, respectively. He has been with School of Advanced Science and Engineering, Department of Electrical Engineering and Bioscience, Waseda University as an assistant professor from 2019. His research interests include energy storage system, AC motor drive, and their application to the DC-electrified railway system. He is a Member of the Institute of Electrical Engineers of Japan (IEEJ) and a Member of IEEE.
Keiichiro Kondo (Senior Member) received the B.S. and Dr. Eng. degrees in electrical engineering from the Faculty of Electrical Engineering, Department of Science and Technology, Waseda University, Tokyo, Japan, in 1991 and 2000, respectively. He joined the Railway Technical Research Institute, Kokubunji, Japan, in 1991, and was engaged in R\&D for power electronics applied to railway vehicle traction. From 2007 to March 2015, he was an Associate Professor of electrical and electronic engineering course with the Graduate School and Faculty of Engineering, Chiba University, Chiba, Japan, where he has been a Professor since April 2015. His current research interests include power electronics, ac motor drive, energy storage devices, wireless power transmission, and their applications to the railway vehicle traction., Prof. Kondo is a Member of the IEEE Industry Applications and Industrial Electronics, and the Institute of Electrical Engineers of Japan. He is a Dr. Eng and Professional Engineer of Japan (Mechanical Engineering, Technical Management). 